\title{
DEMANDAS PIBIC/UFT: 15 ANOS DE TRAJETÓRIA
}

PIBIC / UFT demands: 15 years of trajectory

Demandas PIBIC / UFT: 15 años de trayectoria

Renata Junqueira Pereira, Guilherme Nobre L. do Nascimento; Raphael Sanzio Pimenta

Pró-reitoria de Pesquisa e Pós-Graduação, Universidade Federal do Tocantins, Brasil.

*Correspondência: Pró-reitoria de Pesquisa e Pós-Graduação, Bloco 4, Sala 15, Av. NS 15, 109 Norte, Palmas, Tocantins, Brasil. CEP:77.010-090.E-mail:pibic@uft.edu.br

\section{EDITORIAL}

Instituído em 2014, o Programa Institucional de Bolsas de Iniciação Científica (PIBIC) da Universidade Federal do Tocantins (UFT) lançou em 2020 seu décimo sétimo edital de seleção interna. Em quinze anos de trajetória, observou-se significativo incremento da demanda e também do número de cotas de fomento à iniciação científica.

Entende-se por demanda qualificada, o quantitativo de propostas de planos de trabalho discentes, inscritos no edital de seleção de iniciação científica, que realmente é aprovado para entrar na concorrência, após julgamento pelo comitê de especialistas das áreas de conhecimento internos e externos à Universidade.

O comitê interno atualmente é composto por 60 docentes, representantes dos sete campus da Universidade, nas 4 grandes áreas do conhecimento a saber: Ciências Agrárias; Ciências Biológicas e da Saúde; Ciências Exatas e da Terra e Ciências Humanas, Sociais Aplicadas, Letras e Artes. O comitê interno do PIBIC é selecionado, bianualmente, por Edital com análise de mérito do currículo do pesquisador.

O comitê externo é composto por docentes de outras instituições de ensino nacionais, preferencialmente detentores de bolsa produtividade em pesquisa do $\mathrm{CNPq}$, que são convidados a participarem na avaliação e seleção das propostas que concorrem ao Edital Institucional de Seleção de Bolsistas, emitindo parecer a cada uma das propostas candidatas, por meio de acesso "on line" ao sistema de gerenciamento de propostas de iniciação científica da UFT (SASBIC). Esse comitê recebe as propostas, após previamente apreciadas pelo comitê interno do programa na instituição, participa de uma reunião por videoconferência com os membros institucionais e emite parecer final de recomendação.

As bolsas são concedidas ao PIBIC/UFT tanto pelo Conselho Nacional de Pesquisa (CNPq), como pela própria instituição UFT, por meio da Pró-Reitoria de Pesquisa e PósGraduação (PROPESQ) que destina parte de seu orçamento para bolsas de iniciação científica. Dentre as modalidades de bolsas existentes, a PROPESQ/UFT fomenta apenas bolsas de iniciação científica. Já o CNPq provê também bolsas de iniciação científica em outras 3 modalidades: iniciação científica júnior (PIBICEM), nas ações afirmativas (PIBIC -AF) e no desenvolvimento tecnológico e inovação (PIBITI). 


\section{A TRAJETÓRIA}

A progressão da demanda qualificada por grande área do conhecimento, bem como a evolução do número de bolsas por modalidade (iniciação científica, iniciação científica júnior ensino médio, iniciação científica nas ações afirmativas e desenvolvimento tecnológico e inovação) podem ser observadas nas Figuras 1 e 2.

Figura 1. Demanda qualificada PIBIC, PIVIC e demanda bruta ao longo dos anos do programa.

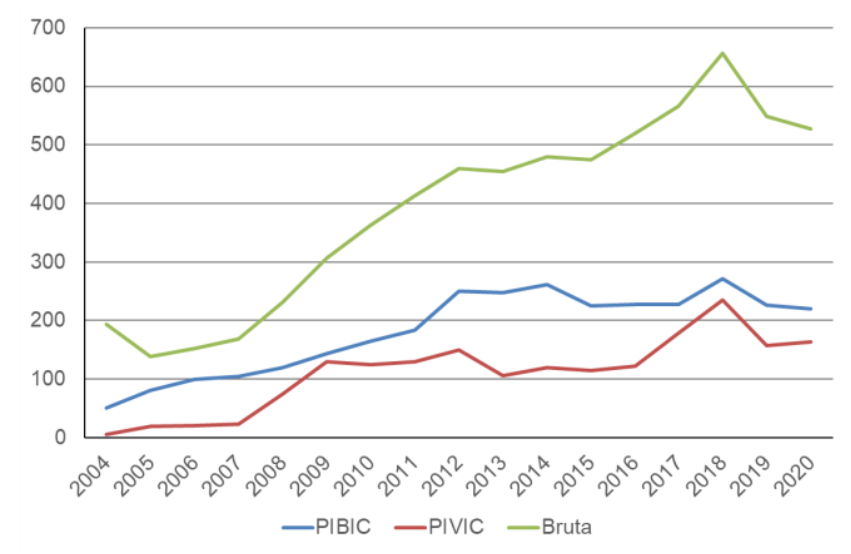

Podemos observar diferentes momentos históricos, ao longo do programa como por exemplo; na grande área do conhecimento de Ciências Biológicas e da Saúde, a trajetória da demanda de projetos se incrementou após 2009 quando foram criados os cursos da área da saúde (enfermagem, medicina e nutrição). Nessa época a área de ciências biológicas se juntou à saúde de forma a perceber um aumento em seu número de propostas submetidas ao edital de seleção de bolsas.

Porém ao longo do programa vários alunos(as) e professores(as) participaram ativamente para o crescimento da pesquisa da
UFT e para o benefício da sociedade Tocantinense uma vez que muitos destes projetos tinham como proposta o estudo e a melhoria de demandas de nosso estado.

Importante ainda salientar a importância dos professores(as) que ajudaram em diferentes momentos na construção e melhoria deste programa tão importante para nossa Instituição e Estado.

Figura 2. Quantidade de bolsas ao longo dos anos do programa.

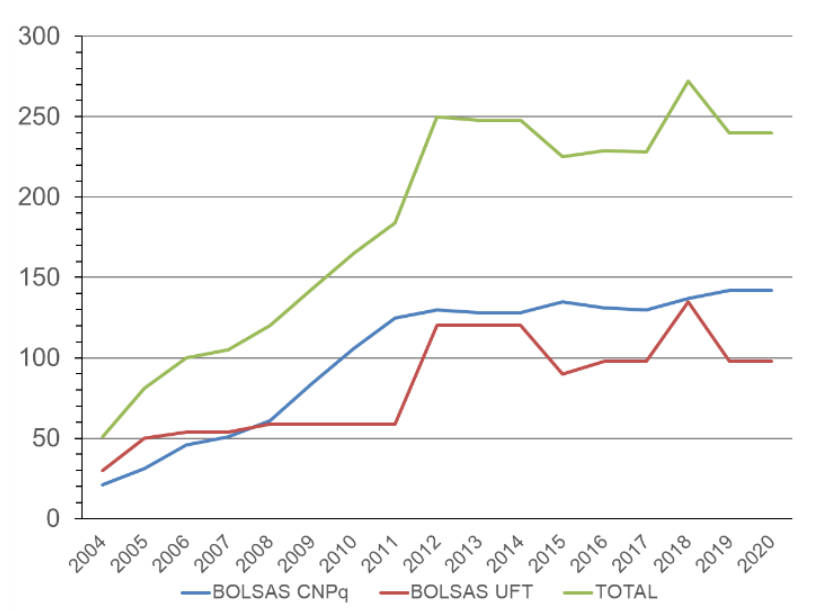

Nossos agradecimentos a todos que participaram e participam deste programa. Em especial também aos servidores da PROPESQ, e demais pró-reitorias, que sempre auxiliaram e auxiliam com as correções e publicações dos editais, suporte no andamento e atendimento aos pesquisadores(as) envolvidos no programa, pois sem vocês este programa também não seria possível

Que tenhamos mais 15 anos de muitas pesquisas! 